Okposio M M Abhulimhen-Iyoha BI

\section{Accuracy of mother's touch in assessing the presence of fever in children}

DOI:http://dx.doi.org/10.4314/njp.v39i2.3

Received: 1st November 2011

Accepted: 25th November 2011

Abhulimhen-Iyoha BI ( $\square)$

Department of Child Health,

University of Benin Teaching

Hospital, Benin City.

E-mail: drblessing4ever@yahoo.com

Tel: +234-8059143792

Okposio M M

Department of Paediatrics, Mariere

Memorial Central Hospital, Ughelli,

Delta State.

E-mail: mattokmatok@yahoo.com

Tel: +234-8127215735

\begin{abstract}
Background: Fever is a very common presenting complaint in children and is of great diagnostic importance. The presence of fever in a child which is often determined by tactile assessment is a major source of concern to caregivers necessitating either the use of medications and /or hospital visitation.

Objective: To test the reliability of tactile assessment of fever by mothers and to ascertain if palpation of a single site or multiple sites affects the accuracy.

Method: The study was conducted at the University of Benin Teaching Hospital, Benin City between July and September 2009 and involved 359 children aged six months to five years. Each child had a tactile assessment of fever by the mother after which the patient's axillary temperature was measured and documented.

Results: One hundred and forty-five
\end{abstract}

mothers $(40.4 \%)$ palpated multiple sites while 214 mothers $(59.6 \%)$ palpated a single site.

Of those that palpated a single site, the head was the most frequently used site $(31 \%)$ while the groin was the least used site $(0.5 \%)$. The sensitivity, specificity, positive predictive value and negative predictive value of mother's perception of fever using a single site were $89.2 \%$, $64.3 \%, 56.9 \%$ and $91.8 \%$ respectively while for mothers who used multiple sites were $89.4 \%, 55.7 \%$, $62.8 \%$ and $86.3 \%$ respectively. No significant difference was found when the values were compared.

Conclusion: Tactile assessment is still a relevant tool in the determination of the presence of fever in children. The use of one or more anatomical sites does not affect its accuracy.

Key Words: Touch, Fever, Accuracy, Children

\section{Introduction}

Fever is a very common complaint in paediatric practice $^{1}$, and it is of great diagnostic importance for paediatricians in developing countries where infectious diseases such as malaria and pneumonia are very prevalent ${ }^{2}$. Many caregivers realize the importance of fever as a symptom and make attempts to seek medical attention $^{3}$. However, because of the relatively low level of literacy and financial capacity for reliable personal thermometers, the use of the thermometer for objective determination of fever is often restricted to the health care facilities ${ }^{4}$.

As a result, the initial diagnosis of fever in a child is often based almost entirely on the assessment by the mother, often by touch. In some cases, maternal report of fever in their wards cannot be confirmed because of either a prior use of antipyretic before arrival in the health facility or intermittent nature of the fever5. If the subjective impression of the mother is erroneous, there may be inappropriate investigation and exposure to drugs with the attendant side effects.

Findings of some cross-sectional studies evaluating subjective touch and objective thermometry have suggested that tactile assessment has the tendency to either overestimate or underestimate the presence of fever. ${ }^{5-7}$ In those studies however, there were obvious differences in the study design and parameters assessed; such as the cutoff value for fever and the site of temperature measurement (rectal versus axillary). In addition, studies that evaluated the accuracy of palpation for fever by healthcare personnel reported an underestimation of the presence of fever ${ }^{6}$ while those comparing maternal touch with thermometer reported overestimation of fever ${ }^{4}$. In a recent study in Northern Nigeria, the sensitivity and specificity of tactile assessment of fever by mothers were $96.3 \%$ and $43.2 \%$ respectively 8 while a study in Ibadan reported sensitivity and specificity, of $95 \%$ and $23 \%$ respectively ${ }^{9}$. In addition, it was also reported that the head and the neck were the most frequently used 
sites for assessment of fever ${ }^{4}$. However, no comparisons were made regarding the accuracy if any between the use of one or more parts of the body. It has been reported that palpating the abdomen or neck more accurately identify the presence of fever whereas, the forehead or face are better for identifying absence of fever ${ }^{10}$. Therefore it is being suggested that the palpation of multiple sites may enhance the diagnostic capability of maternal touch in the detection of fever. ${ }^{10}$ The current study therefore seeks to ascertain if palpating a single site or multiple sites affects its accuracy.

\section{Patients and Methods}

The study was a cross-sectional one carried out at the Children Emergency Room (CHER) of the University of Benin Teaching Hospital (UBTH), Benin City between July and September 2009.

Subjects consisted of children aged six months to five years presenting to CHER with various complaints. Those whose mothers had used a thermometer at home or had given an antipyretic in the preceding six hours prior to presentation in CHER were excluded to avoid bias.

Each mother was interviewed using a structured questionnaire in which the socio-demographic characteristics as well as her usual method of fever determination were obtained. We also sought to know if the mothers had functional thermometers. The mothers were asked to palpate their children to ascertain whether they were febrile. The site(s) of palpation were noted. The palpation was either on a single site or on multiple sites. Thereafter, the patient's axillary temperature was measured and documented. Fever was defined as axillary temperature of $\geq 37.5 \mathrm{oC}$ according to the World Health Organization expert study group ${ }^{11}$.

Ethical approval was obtained from the Ethics Committee of UBTH and written informed consent was obtained from mothers of subjects.

Data was entered and analysed using SPSS 16.0 to determine the sensitivity, specificity, positive predictive value (PPV) and negative predictive value (NPV) of mothers' impression of fever. The sensitivity, specificity, PPV and NPV of a single site palpation was also compared with that of multiple sites using a McNemar test and p-value of less than $0.05(<0.05)$ was considered statistically significant.

\section{Results}

Of the 511 children whose mothers gave consent to participate in the study, 131 had taken antipyretics within six hours prior to presentation while 21 already had their temperature confirmed by thermometry before presentation. Thus, a total of 359 children were enrolled for the study. All the children were brought by their mothers. Of these, 213 (59.3\%) were males while 146 (40.7\%) were females giving a $\mathrm{M}$ : F ratio of $1.5: 1$. The mean age was $18.9 \pm 1.4$ months with median age being 15 months.

One hundred and forty-five mothers $(40.4 \%)$ palpated multiple sites while 214 mothers $(59.6 \%)$ palpated a single site. Of those that palpated a single site, the forehead was the most $(31 \%)$ palpated site while the least palpated was the groin $(0.5 \%)$ Table 1

Table 1: Predictive indices of palpation at different sites for fever

Sites of palpation Fever by Palpation Fever by Thermometry Present Present Sens. Spec. PPV NPV

\begin{tabular}{lcccccc} 
Forehead & 35 & 25 & 96.0 & 75.6 & 70.6 & 96.6 \\
Neck & 30 & 18 & 83.3 & 63.4 & 50.0 & 89.7 \\
Abdomen & 34 & 23 & 82.6 & 58.3 & 55.9 & 84.0 \\
Chest & 12 & 6 & 100 & 40 & 50 & 100 \\
Extremities & 4 & 2 & 50 & 70 & 25 & 87.5 \\
Groin & 1 & 0 & & & & \\
Total & 116 & 74 & & & & \\
\hline
\end{tabular}

Sens $=$ Sensitivity

Spec $=$ Specificity

$\mathrm{PPV}=$ Positive Predictive Value

$\mathrm{NPV}=$ Negative Predictive Value

Of the 145 children whose mothers palpated multiple sites, fever was deemed present in $94(64.8 \%)$ by maternal palpation, but only $66(45.5 \%)$ had fever when temperature was confirmed using a thermometer. In the same vein, the mothers affirmed the absence of fever in $51(35.2 \%)$ of the children but $79(54.5 \%)$ were actually afebrile when temperature was confirmed by thermometery. The sensitivity and specificity of mother's determination of fever by palpation were $89.4 \%$ and $55.7 \%$ respectively. The positive predictive value was $62.8 \%$, and a negative predictive value of $86.3 \%$ (Table 2).

Table 2: Mother's Determination of Fever by Palpation

\begin{tabular}{lccc}
\hline & $\begin{array}{c}\text { Fever present } \\
\text { by } \\
\text { thermo meter } \\
\mathrm{n}(\%)\end{array}$ & $\begin{array}{c}\text { Fever absent } \\
\text { by } \\
\text { thermo meter } \\
\mathrm{n}(\%)\end{array}$ & Total \\
& $\mathrm{n}(\%)$ \\
\hline $\begin{array}{l}\text { Fever present } \\
\text { by palpation } \mathrm{n}(\%)\end{array}$ & $59(41 \%)$ & $35(24 \%)$ & $94(65 \%)$ \\
$\begin{array}{l}\text { Fever absent } \\
\text { by palpation } \mathrm{n}(\%)\end{array}$ & $7(5 \%)$ & $44(30 \%)$ & $51(35 \%)$ \\
\begin{tabular}{l} 
Total $\mathrm{n}(\%)$ \\
\hline
\end{tabular} & $66(46 \%)$ & $79(54 \%)$ & $145(100 \%)$ \\
\hline
\end{tabular}

Sensitivity $59 / 66 \times 100=89.4 \%$

Specificity $44 / 79 \times 100=55.7 \%$

Positive predictive value $(\mathrm{PPV}) 59 / 94 \times 100=62.8 \%$

Negative predictive value (NPV) $44 / 51 \times 100=86.3 \%$ 
of Multiple Sites Compared with Thermometry

Among the 214 children whose mothers palpated a single site to detect fever, the mothers affirmed the presence of fever in $116(54.2 \%)$ but only $74(34.6 \%)$ had fever by thermometry. In contrast, the mothers affirmed the absence of fever in $98(45.8 \%)$ children while 140 $(65.4 \%)$ were non-febrile by thermometry, giving a sensitivity of $89.2 \%$, specificity of $64.3 \%$, positive predictive value of $56.9 \%$, and a negative predictive value of $91.8 \%$ (Table 3).

Table 3: Mother's Determination of Fever by Palpation of a Single Site Compared with Thermometry

\begin{tabular}{ccc}
\hline $\begin{array}{c}\text { Fever present by Fever absent by } \\
\text { thermometer }\end{array}$ & Total \\
$\mathrm{n}(\%)$ & $\mathrm{n}(\%)$ & $\mathrm{n}(\%)$ \\
\hline
\end{tabular}

\begin{tabular}{lccc}
$\begin{array}{l}\text { Fever present by } \\
\text { palpation }\end{array}$ & $66(30.8 \%)$ & $50(23.4 \%)$ & $116(54.2 \%)$ \\
$\begin{array}{l}\text { Fever absent by } \\
\text { palpation }\end{array}$ & $8(3.7 \%)$ & $90(42.1 \%)$ & $98(45.8 \%)$ \\
Total & $74(34.5 \%)$ & $140(65.5 \%)$ & $214(100 \%)$ \\
\hline
\end{tabular}

Sensitivity $66 / 74 \times 100=89.2 \%$

Specificity $90 / 140 \times 100=64.3 \%$

Positive Predictive Value (PPV) $66 / 116 \times 100=56.9 \%$

Negative Predictive Value (NPV) $90 / 98 \times 100=91.8 \%$

Comparison of the sensitivity, specificity, PPV and NPV of a single site palpation with that of multiplesites palpation showed no significant difference between the corresponding parameters (Sensitivity: $\mathrm{x}^{2}=0.0015, \mathrm{p}=0.97$; Specificity: $\mathrm{x}^{2}=1.5689, \mathrm{p}=0.21 ; \mathrm{PPV}: \mathrm{x}^{2}=0.7424$, $\mathrm{p}=0.39 ; \mathrm{NPV}: \mathrm{x}^{2}=1.1462, \mathrm{p}=0.28$ )

The usual method of fever determination was palpation by $328(91.4 \%)$ mothers, thermometer by 25 (7\%) mothers and six (1.6\%) mothers used both palpation and thermometry. Fifty seven (15.9\%) of the mothers owned thermometers but thirty one make use of them. The results also show that $272(75.8 \%)$ of the mothers who use palpation for fever determination felt it was very reliable, $28(7.8 \%)$ said it was not reliable while another 28 $(7.8 \%)$ did not know if it was a reliable method or not. However, all those who use thermometer felt thermometry was a very reliable method of fever determination

\section{Discussion}

Identification of fever in children by palpation is still a very common practice among mothers and care givers. It is usually the first method used to check for the presence or absence of fever in a child suspected to be sick. This was clearly shown in the current study where $91.4 \%$ of the mothers relied on the practice for fever determination. The reason for choosing this method may be due to the ease with which palpation can be performed and interpreted as well as the perception by more than three quarters of the mothers that it is very reliable method. In most cases, medications such as antipyretics and anti- malarials are commenced on the basis of mother's perception of the presence of fever. This was also seen in this study going by the high number of mother-child pairs excluded from the study because of prior use of antipyretic.

The current study demonstrated that the sensitivity and specificity of maternal assessment of fever by palpation of a single site was not significantly different from that by mothers who used multiple sites $(\mathrm{p}=0.97$ and $\mathrm{p}=0.21$ ). The percentage of children misjudged by mothers was similar for both single and multiple site palpation. Single site palpation incorrectly adjudged $19.6 \%$ of the children as febrile while multiple site palpation incorrectly adjudged $19.3 \%$ of the children as febrile. The $89.2 \%$ sensitivity of maternal tactile assessment using a single site is similar to those reported by Ernst and Phil$\operatorname{lip}^{7}(90.0 \%)$, Wammanda et $\mathrm{al}^{8}(96.3 \%)$; Akinbami et $\mathrm{al}^{9}(94.6 \%)$ and Nwanyanwu et $\mathrm{al}^{12}(97.3 \%)$. However, the palpation of multiple sites for fever determination did not improve the sensitivity.

This is in contrast to an earlier report by Singh and Sood $^{10}$ that palpation of multiple sites improves sensitivity to $100 \%$. The reason for the difference in finding when compared to our study could be because only a small population of the mothers [(12) $(10.3 \%)]$ used multiple sites in their study, as against $145(40.4 \%)$ in the present study.

The current study has also demonstrated that the ability of the mother to correctly identify non- febrile children among those without fever was not significantly enhanced by the palpation of a single or multiple anatomical sites. The specificity of single site palpation of $64.3 \%$ is higher than reports from studies by Wammanda et $\mathrm{al}^{8}(43.2 \%)$, Akinbami et $\mathrm{al}^{9}(23 \%)$ and Nwanyanwu et $\mathrm{al}^{12}(19.2 \%)$. However, the specificity of multiple sites palpation of 55\% in the present study is lower than the $92 \%$ reported by Singhi and Sood. ${ }^{10}$ The reason for the differences in finding could be as a result of methodological variations. For instance, the cut-off value of fever was variable, as well as site of temperature measurement. While axillary temperature of $\geq 37.5 \mathrm{oC}$ defined fever in the present study, Akinbami et $\mathrm{al}^{9}$ and Nwanyanwu ${ }^{12}$ used rectal temperature of $38 \mathrm{oC}$ while Wammanda et $\mathrm{al}^{8}$ used axillary temperature of $\geq 37.2 \mathrm{oC}$.

The negative predictive values for single and multiple sites in this study were $91.8 \%$ and $86.3 \%$ respectively. The difference is similar to that obtained by Wammanda et al $(86.4 \%)^{8}$ and Nwanyanwu et al $(92.5 \%)^{12}$ but are much higher than the $73 \%$ obtained by Akinbami et $\mathrm{al}^{9}$. The NPV in this study which implies the likelihood of a child adjudged to be afebrile by the mother to be truly afebrile is an important parameter. The implication is that if a mother says the child does not have fever, her history is most likely reliable.

The predictive value of positive test in the present study which implies the ability of a mother to detect fever by 
palpation when a child was truly febrile is $56.9 \%$ using a single anatomical site. This is remarkably lower than $76 \%$ reported by Wammanda et $\mathrm{al}^{8}$ and $66 \%$ reported by Akinbami et $\mathrm{al}^{9}$ The use of multiple sites, however, only marginally improved the PPV to $62.8 \%$. The PPV as reported by Wammanda et $\mathrm{al}^{8}$ could have been influenced by the prevalence of fever in their study sample given that only children with fever as part of their complaints were enrolled. However, based on our finding, it may be necessary, where possible, to always confirm maternal report of fever by a more objective measurement.

The current study has shown the forehead to be the most used site for tactile assessment of fever followed by the neck and abdomen. About a third of the mothers in this study who palpated a single site for fever determination used the forehead. This, therefore, corroborates reports of previous studies which also found the head and neck to be the commonest anatomical sites used for tactile assessment of fever ${ }^{4}$. Again, given its high sensitivity and NPV, the forehead is probably the most reliable site for tactile assessment to exclude fever when the child is truly afebrile. However, the number of mothers who used only the forehead was rather small compared to the number of mothers studied. Therefore, an enlarged study set out to compare the sensitivity, specificity, PPV and NPV of the different anatomical sites for tactile assessment of fever may be required to make any recommendation. The act of raising a child's dress to palpate may have contributed to its low sensitivity. This is because the part of the body covered by clothing will likely feel warm to touch such that there is a high tendency to over diagnose fever in this group of children.

\section{Conclusion}

tactile assessment of fever in children by their mothers is still an essential screening tool to determine the presence or absence of fever. The use of one or more anatomical sites did not significantly affect the sensitivity, specificity, positive predictive value and the negative predictive value of this type of temperature determination. The head which receives large amount of the blood may serve as a good site to assess the body temperature by touch. The use of the abdomen, though a common site was not as sensitive. In spite of the observed limitations of this method of fever determination, a mother's complaint of fever in a child must not be discountenanced.

Conflict of interest: None

Funding: None:

\section{Acknowledgement}

We acknowledge the resident doctors and nursing staff of the Paediatric Emergency Unit of UBTH for their contributions to the management of these patients. The children recruited for the study and their mothers are also acknowledged for their co-operation.

\section{References}

1. Schmitt BD. Fever in childhood. Pediatrics 1984;74:929-36

2. O'Dempsey TJ, McArdle TF, Laurence BE et al. Overlap in the clinical features of pneumonia and malaria in African children. Trans R Soc Trop Med Hyg 1993;87:662 $-5$

3. Poirer MP, Collins PE, McGuire E. Fever Phobia:A survey of caregiver of children seen in a Pediatric Emergency Department. Clin Pediatr 2010;49:530-34

4. Katz-Sidlow RJ, Rowberry JP, Ho M. Fever determination in young infant: prevalence and accuracy of parental palpation. Pediatr Emerg care 2009;25:12-4
5. Teng CL, Ng CJ, Nik-Sherina et al. The accuracy of mother's touch to detect fever in children: A systematic review. J Trop Pediatr 2008;54:70-3

6. Bergeson PS, Steinfeld HJ. How dependable is palpation as a screening method for fever? Clin Pediatr 1974;13:350-1

7. Ernst TN, Phillip M.Temperature assessment by parental palpation. Am J Dis Child 1985;139:546-7

8. Wammanda RD, Onazi SO. Ability of the mother to assess the presence of fever in their children: Implication for the treatment of fever under the IMCI guidelines. Ann Afr Med 2009;8:173-76
9. Akinbami FO, Adebola EO, Olukemi OT et al. Detection of fever in children emergency care: Comparisons of tactile and rectal temperatures in Nigerian children. BMC Res Notes 2010;3:108

10. Singhi S, Sood V. Reliability of subjective assessment of fever by mothers. Indian Pediatr 1990; 27:811-15.

11. Moorthy V, Reed Z, Smith PG. Measurement of malaria vaccine efficacy in phase 3 trials: report of a WHO Consultation. Vaccine 2007;25:5115-23

12. Nwanyanwu OC, Ziba C, Redd C et al. Palpation as a method of fever determination in malawian children who are less than 5 years: how reliable is it? Ann Trop Med Parasitol 1997;91:359-63 